\title{
The Demographic Transition: Causes and Consequences
}

\author{
Oded Galor* \\ Brown University
}

December 31, 2010

\begin{abstract}
This paper develops the theoretical foundations and the testable implications of the various mechanisms that have been proposed as possible triggers for the demographic transition. Moreover, it examines the empirical validity of each of the theories and their significance for the understanding of the transition from stagnation to growth. The analysis suggests that the rise in the demand for human capital in the process of development was the main trigger for the decline in fertility and the transition to modern growth

Keywords: Demographic trnasition, Gender Gap, Human capital, Fertility, Mortality, Unified Growth Theory

JEL Classification Numbers: O10, J1
\end{abstract}

*Department of Economics, Brown University, Providence, RI 02912 (email: Oded_Galor@brown.edu). 


\section{Introduction}

The demographic transition has swept the world since the end of the nineteenth century. The unprecedented increase in population growth during the Post-Malthusian Regime has been ultimately reversed, bringing about significant reductions in fertility rates and population growth in various regions of the world.

The demographic transition has enabled economies to convert a larger portion of the gains from factor accumulation and technological progress into growth of income per capita. It enhanced labor productivity and the growth process via three channels. First, the decline in population growth reduced the dilution of the growing stocks of capital and infrastructure, increasing the amount of resources per capita. Second, the reduction in fertility rates permitted the reallocation of resources from the quantity of children toward their quality, enhancing human capital formation and labor productivity. Third, the decline in fertility rates affected the age distribution of the population, temporarily increasing the fraction of the labor force in the population and thus mechanically increasing productivity per capita.

This paper examines various mechanisms that have been proposed as possible triggers for the demographic transition and assesses their empirical significance in understanding the transition from stagnation to growth. Was the onset of the fertility decline an outcome of the rise in income during the course of industrialization? Was it triggered by the reduction in mortality rates? Was it fueled by the rise in the relative wages of women? Or was it an outcome of the rise in the demand for human capital in the second phase of industrialization? ${ }^{1}$

\section{The Rise in the Level of Income Per Capita}

The rise in income per capita prior to the decline in fertility has led some researchers to argue that the reduction in fertility was triggered by the rise in income in the process of industrialization. In particular, Becker (1960) advanced the argument that the decline in fertility was a by-product of the rise in income and the associated rise in the opportunity cost of raising children. His thesis suggests that the rise in income induced a fertility decline because the positive income

\footnotetext{
${ }^{1}$ The Princeton Project on the Decline of Fertility in Europe, carried out in the 1960s and 1970s, attempted to characterize the decline of fertility in Europe during the nineteenth and early twentieth centuries. The project suggests that social and economic forces played little role in the onset of fertility transition. The methodology used in this research has been discredited over the years (e.g., Guinnane et al., 1994; Brown and Guinnane, 2007), and economic forces are currently viewed as central to this transition.
} 
effect on fertility was dominated by a negative substitution effect brought about by the rising opportunity cost of raising children. Similarly, Becker and Lewis (1973) postulated that the income elasticity with respect to investment in children's education was greater than that with respect to the number of children, and hence the rise in income led to a decline in fertility along with an increase in the investment in each child.

However, this preference-based theory is fragile from a theoretical viewpoint and unsatisfactory from an intellectual one. It hinges on the supposition that individuals' preferences reflect an innate bias against child quantity beyond a certain level of income. ${ }^{2}$ Most critically, it generates testable predictions that appear inconsistent with the evidence.

\subsection{The Theory and its Testable Predictions}

Consider a household that generates utility from consumption, $c$, and the number of (surviving) children, $n$. The household is endowed with one unit of time and it generates an income, $y$, if its entire unit of time is supplied to the labor market. Suppose that raising children is time intensive and the entire cost associated with raising each child is a fraction $\tau$ of the parental unit-time endowment. ${ }^{3}$

Hence, the household's consumption equals the household's labor income; that is, $c=$ $(1-\tau n) y$. Alternatively, the household's budget constraint can be written in the conventional form

$$
\tau y n+c \leq y
$$

where the price of a child is the opportunity cost associated with raising it, $\tau y .{ }^{4}$

A rise in the household's earning capacity (per unit of time), $y$, generates two conflicting effects. On the one hand, the increase in $y$ generates a positive income effect, which operates to increase the number of children (as long as children are viewed as a normal good). On the other hand, the rise in $y$ generates a negative substitution effect, which reflects the increase in the opportunity cost of raising a child, $\tau y$. If preferences are homothetic (i.e., preferences are not inherently biased toward either consumption or children as income increases), the income

\footnotetext{
${ }^{2}$ One can attribute most changes in economic regimes to changes in the nature of preferences. However, since preferences, as opposed to choices, are largely unobservable, theories that rely on changes in preferences are not refutable.

${ }^{3}$ Alternatively, $\tau y$ can be viewed as a monetary cost associated with raising each child by paying for a fraction $\tau$ of a caretaker's time. The addition of nontime costs would not affect the qualitative insights.

${ }^{4}$ The price of consumption is normalized to 1 .
} 
effect and substitution effect cancel one another. For instance, if the household's preferences are represented by a log-linear utility function, i.e., ${ }^{5}$

$$
u=\gamma \ln n+(1-\gamma) \ln c
$$

where $0<\gamma<1$ is a parameter; then the household's optimal number of children is independent of income;

$$
n=\gamma / \tau \text {. }
$$

Thus, a priori, in contrast to the prediction of the Beckerian theory, the rise in income may have no effect on the number of children. The Beckerian theory, therefore, is nonrobust, as it rests on an implicit set of assumptions that assure that the substitution effect dominates as income rises.

Nevertheless, independent of its theoretical fragility, one can examine the Beckerian theory based on its testable predictions. If indeed the substitution effect dominates at sufficiently high levels of income, then the theory suggests that the differential timing of the fertility decline across countries (in similar stages of development) would reflect differences in income per capita. Furthermore, the level of fertility among individuals within a given economy would reflect their income levels.

Thus, the theory generates two major testable implications:

(i) Across countries that are similar in sociocultural characteristics (and thus in noneconomic factors that may affect fertility decisions), the timing of the fertility decline is inversely related to the level of income per capita.

(ii) Within an economy, the number of (surviving) children across households is inversely related to their levels of income.

\section{$2.2 \quad$ The Evidence}

Remarkably, the theory appears counterfactual on both counts. As depicted in Figures 4.1 and 4.2, the decline in fertility occurred in the same decade across Western European countries that differed significantly in their income per capita. In 1870, on the eve of the demographic transition,

\footnotetext{
${ }^{5}$ For simplicity, it is assumed that parents derive utility from the expected number of surviving offspring and that the parental cost of child rearing is associated only with surviving children. The introduction of costs associated with nonsurviving children, or risk aversion, would not affect the qualitative features of the theory.
} 
England and the Netherlands were the richest countries in Western Europe, enjoying GDP per capita of $\$ 3,190$ and $\$ 2,760$, respectively (Maddison,.${ }^{6}$ In contrast, Germany and France, which experienced the onset of a decline in fertility in the same decade as England and the Netherlands, had in 1870 a significantly smaller GDP per capita of $\$ 1,840$ and $\$ 1,880$ respectively (i.e., only about $60 \%$ of the level in England). Moreover, Sweden and Norway's GDP per capita were only about $40 \%$ of that of England in 1870, and Finland's GDP per capita was merely a third of the level in England. Nevertheless, the onset of the fertility decline in these poorer economies occurred in the same decade as in England. ${ }^{7}$

The simultaneity of the demographic transition across Western European countries that differed significantly in their incomes per capita suggests that the high levels of income reached by these countries in the Post-Malthusian Regime played a very limited role, if any, in the onset of the demographic transition, refuting the first testable implication of Beckerian theory.
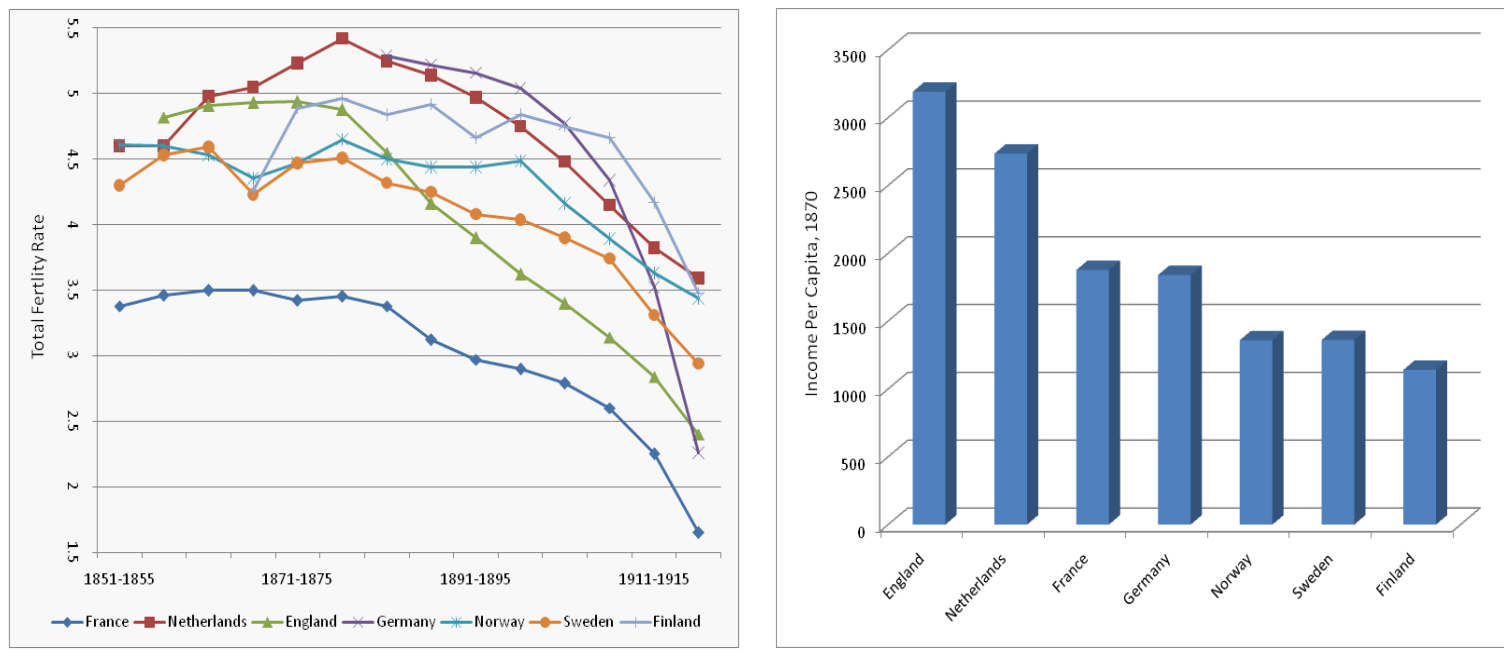

Figure 1. The Demographic Transition Across Western Europe.

Data Sources: Chesnais (1992) and Maddison (2008).

Moreover, the evidence presented by Murtin (2009) (based on a panel of countries during 1870-2000) shows that income per worker was positively associated with fertility rates, once controls were introduced for mortality rates and education.

\footnotetext{
${ }^{6}$ GDP per capita was measured in 1990 international dollars.

${ }^{7}$ One could sensibly argue that the income thresholds at which the substitution effect dominates differ across this set of countries due to sociocultural and distributional factors. However, the likelihood that these differential thresholds would be reached in the same decade across a large number of countries appears remote.
} 
Recent empirical examinations of the various factors that contributed to the demographic transition within an economy also refute the second implication of the Beckerian theory. In particular, cross-sectional evidence from France and England does not lend support to the theory. Murphy (2009) finds, based on panel data from France during 1876-1896, that income per capita had a positive effect on fertility rates during France's demographic transition, accounting for education, the gender literacy gap, and mortality rates. Moreover, a quantitative analysis of the demographic transition in England, conducted by Fernández-Villaverde (2001), suggests that, in contrast to the Beckerian theory, the force associated with a rise in income would have led to an increase in fertility rates rather than to the observed decline in fertility.

\section{The Decline in Infant and Child Mortality}

The decline in infant and child mortality that preceded the reduction in fertility and population growth in most advanced economies, with the notable exceptions of France and the United States, has been viewed as a plausible explanation for the onset of the decline in population growth during the demographic transition. Nevertheless, this hypothesis appears to be nonrobust theoretically and inconsistent with historical evidence.

\subsection{The Theory and its Testable Predictions}

Consider a household that generates utility from consumption, $c$, and the number of surviving children, $n$. Suppose that each child faces a probability $\theta$ of surviving infancy. Given the (continuous) number of children that the household will bear, $n^{b}$, the number of surviving children is $n=\theta n^{b}$. The household's preferences are represented by log-linear utility function: ${ }^{8}$

$$
u=\gamma \ln n+(1-\gamma) \ln c ; \quad 0<\gamma<1
$$

Moreover, the household is endowed with one unit of time, and it generates an income, $y$, if its entire unit of time is supplied to the labor market.

Suppose that raising children is time intensive and the cost associated with raising each surviving child is a fraction $\tau$ of the parental unit-time endowment, whereas the cost of raising a

\footnotetext{
${ }^{8}$ If the number of children is modeled as an integer rather than a continuous variable, then the maximization problem would have to be modified to account for uncertainty (e.g., Kalemli-Ozcan, 2002). Nevertheless, the qualitative prediction as outlined in this section would not be altered.
} 
nonsurviving child is 0 . The household's budget constraint is therefore

$$
\tau y n+c \leq y
$$

where the price of a surviving child is the opportunity cost associated with raising a child, $\tau y$.

The household's optimal number of surviving children is therefore

$$
n=\gamma / \tau,
$$

whereas the number of children born to the household, $n^{b}$, is

$$
n^{b}=\gamma /(\tau \theta)
$$

Hence, a decline in the child mortality rate, or equivalently an increase in the survival probability of a child, $\theta$, mechanically reduces the level of household fertility, $n^{b}$, but (in the absence of uncertainty) has no effect on the number of surviving children, $n$.

The theory suggests that:

(a) Mortality rates have a positive effect on total fertility rates.

(b) Declines in mortality would not lead to a reduction in the number of surviving offspring unless the number of surviving children is uncertain and the following conditions are satisfied:

(i) There exists a precautionary demand for children (i.e., individuals are risk averse with respect to the number of surviving offspring and thus hold a buffer stock of children in a high-mortality environment).

(ii) Risk aversion with respect to consumption is not larger than risk aversion with respect to the number of surviving children. ${ }^{9}$

(iii) Sequential fertility (i.e., replacement of nonsurviving children) is modest.

(iv) Parental resources saved from the reduction in the number of children that do not survive to adulthood are not channeled toward childbearing. ${ }^{10}$

\footnotetext{
${ }^{9}$ In contrast, evolutionary forces would lead to the selection of preferences with higher risk aversion with respect to consumption (Galor and Michalopoulos, 2006).

${ }^{10}$ Furthermore, if the physiological constraint on the feasible number of births per woman is binding for some households under a high mortality regime, a reduction in mortality would operate to increase the number of surviving offspring.
} 


\subsection{The Evidence}

While it is plausible that mortality rates were one of the factors that affected the level of fertility throughout human history, historical evidence does not lend credence to the argument that the decline in mortality accounts for the reversal of the positive historical trend between income and fertility and for the decline in population growth (i.e., fertility net of mortality).

The decline in mortality in Western Europe started nearly a century prior to the decline in fertility and was associated initially with increasing fertility rates in some countries. In particular, as depicted in Figure 4.2, the decline in mortality started in England in the 1730s and was accompanied by a steady increase in fertility rates until 1800. The sharp decline in fertility in the course of the demographic transition occurred during a period in which income per capita maintained its earlier positive trend, while mortality declines maintained the course that had existed in the 140 years preceding the decline in fertility. ${ }^{11}$ The sharp reversal in the fertility patterns in Western European countries in the 1870s, in the context of this stable pattern of mortality decline, therefore, suggests that the demographic transition was prompted by a different universal force.
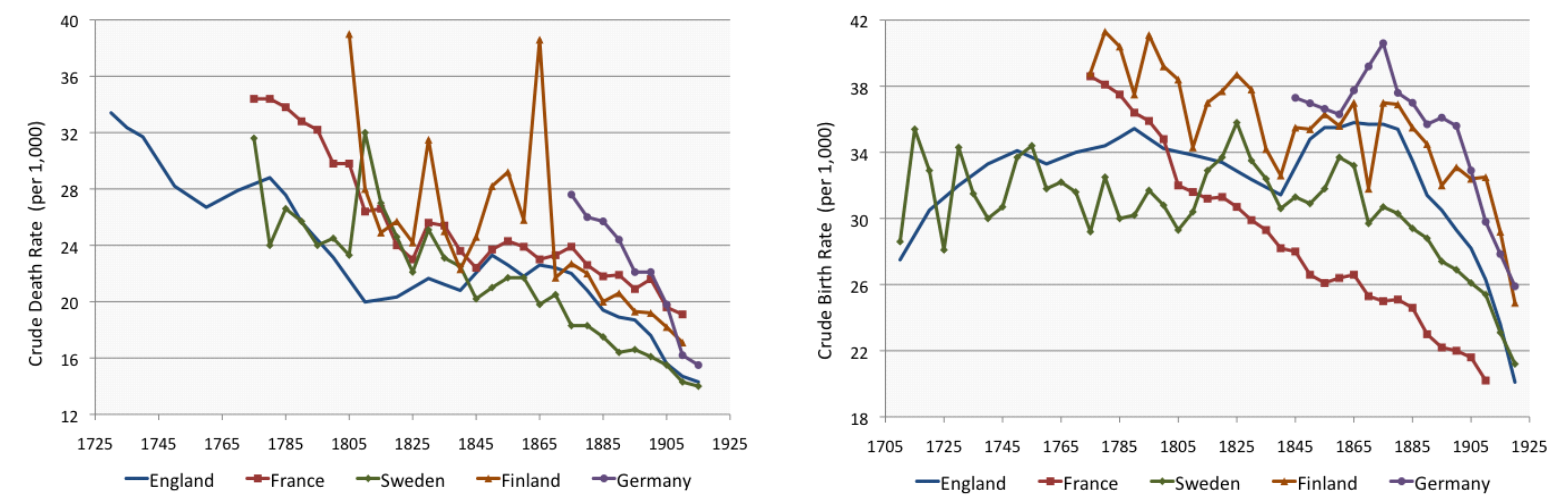

Figure 2. Mortality and Fertility across Western Europe, 1705-1925.

Data sources: Chesnais (1992); Maddison (2008).

Recent quantitative and empirical evidence supports the viewpoint that a decline in infant

\footnotetext{
${ }^{11}$ One could argue that the decline in mortality was not internalized into the decisions of households who had difficulties separating a temporary decline from a permanent one. However, this argument is highly implausible, given that mortality declined monotonically for nearly 140 years prior to the demographic transition. It is inconceivable that six generations of households did not update information about mortality rates in their immediate surroundings, keeping the collective memories about mortality rates prevalent more than a century earlier.
} 
mortality rates was not the trigger for the decline in net fertility during the demographic transition. Doepke (2005), using the mortality and fertility data from England during 1861-1951, finds that in the absence of changes in other factors, the decline in child mortality during this time should have resulted in a rise in net fertility rates, in contrast to the evidence. A similar conclusion about the insignificance of declining mortality for determining the decline in fertility during the demographic transition is reached in the quantitative analysis of Fernández-Villaverde (2001). Moreover, Murphy (2009) suggests, based on panel data from France during 1876-1896, that the mortality rate had no effect on fertility during France's demographic transition, accounting for education, income, and the gender literacy gap. ${ }^{12}$

Importantly, it is the reduction in net fertility and thus in population growth that is most relevant from the viewpoint of the theory of economic growth. However, in light of the implausible set of conditions that must be met for a decline in mortality rates to generate a decline in net fertility, the observed sharp decline in the number of surviving offspring (i.e., net reproduction rate) during the demographic transition raises further doubts about the significance of mortality declines in triggering the onset of the decline in population growth. ${ }^{13}$

\section{The Rise in the Demand for Human Capital}

The gradual rise in demand for human capital during the second phase of industrialization and its close association with the timing of the demographic transition has led researchers to argue that the increasing role of human capital in the production process induced households to increase their investment in the human capital of their offspring, leading to the onset of the fertility decline.

Galor and Weil (1999, 2000) and Galor and Moav (2002) argue that the acceleration in the rate of technological progress during the second phase of the Industrial Revolution increased the demand for human capital and induced parents to invest more heavily in the human capital of their offspring. ${ }^{14}$ This increase in the rate of technological progress and the associated increase in

\footnotetext{
${ }^{12}$ In contrast, Eckstein et al. (1999)'s structural quantitative analysis of the demographic transition in Sweden suggests that mortality decline played a role in the demographic transition. Their underlying theoretical structure requires conditions (iii) and (iv) as well as specific interactions among mortality, wages, and the return to human capital.

${ }^{13}$ The evolution of fertility and mortality in less developed economies has been partly affected by policies advanced by developed economies. A comprehensive overview of these patterns is provided by Schultz (1997).

${ }^{14}$ The effect of the rise in demand for human capital on parental choice of quality and quantity of offspring is discussed by Becker (1981). Becker et al. (1990) explore the role of luck in determination of the relative timing of the demographic transition and thus the wealth of nations. As they argue on page S13, "Many attempts to
} 
parental income and demand for human capital brought about two effects on population growth.

On the one hand, the rise in income eased households' budget constraints and provided more resources for quality as well as quantity of children. On the other hand, it induced a reallocation of these increased resources toward child quality. In the course of transition from the Malthusian Epoch, the effect of technological progress on parental income dominated, and population growth as well as the average population quality increased. Ultimately, further increases in the rate of technological progress induced a reduction in fertility, generating a decline in population growth and an increase in the average level of education.

Suppose that individuals generate utility from the quantity and the quality of their children as well as from their own consumption. They choose the number of children and their quality in the face of a constraint on the total amount of time that can be devoted to child-raising and labor-market activities. A rise in parental income due to a rise in the demand for parental human capital would generate, in contrast to Becker and Lewis (1973), conflicting income and substitution effects that would not necessarily trigger a decline in fertility. However, the rise in the future demand for the children's human capital would lead to a pure substitution effect, which would induce parents to substitute quality for quantity of children.

\subsection{The Theory and Its Testable Predictions}

Consider a household that generates utility from consumption, $c$, the number of (surviving) children, $n$, and the human capital of each child, $h$. Suppose that preferences are represented by a log-linear utility function ${ }^{15}$

$$
u=(1-\gamma) \ln c+\gamma[\ln n+\beta \ln h]
$$

where $0<\gamma<1$ and $0<\beta<1$ are constant parameters.

explain why some countries have had the best economic performance in the past several centuries give too little attention to accidents and good fortune." In their theory a major shock shifts the economy from the basin of attraction of a high-fertility to a low-fertility steady-state equilibrium, generating, counterfactually, a monotonic decline in fertility rates along with a monotonic rise in income per capita. However, existing evidence shows that the process of industrialization and the associated increase in income per capita were accompanied by a sharp increase in population growth, prior to its decline during the course of the demographic transition. Moreover, although they define the low output, high population growth steady state as a Malthusian steady-state equilibrium, it has none of the features of a Malthusian equilibrium; population growth rate is not at the replacement level it is, counterfactually, higher than that in the beginning of the demographic transition. Furthermore, a small positive shock to income when the economy is in the "Malthusian" steady state initially decreases fertility, in contrast to the central aspect of Malthusian equilibrium.

${ }^{15}$ Once again, it is assumed that parents derive utility from the expected number of surviving offspring and the parental cost of child rearing is associated only with surviving children. The introduction of costs associated with non-surviving children, or risk aversion, would not affect the qualitative features of the theory. 
Let $\tau^{q}+\tau^{e} e$ be the time cost of raising a child with a level of education (quality) $e$. That is, $\tau^{q}$ is the fraction of the household's unit-time endowment that is required to raise a child, regardless of quality, and $\tau^{e}$ is the fraction of the household's unit-time endowment that is required for each unit of education per child.

The household is endowed with one unit of time. It generates an income, $y$, if its entire unit of time is supplied to the labor market. The household's potential income, $y$, is divided between expenditure on child rearing (quantity and quality) and consumption, $c$. The household's budget constraint is therefore

$$
y n\left(\tau^{q}+\tau^{e} e\right)+c \leq y
$$

where the price of a child is the opportunity cost associated with raising it, $y\left(\tau^{q}+\tau^{e} e\right)$.

Suppose that individuals' level of human capital is determined by their quality (education) as well as by the technological environment. Technological progress reduces the adaptability of existing human capital to a new technological environment. Education, however, lessens the adverse effects of technological progress. In particular, the time required for adaptation to a new technological environment diminishes with the level of education and increases with the rate of technological change.

Suppose that the level of human capital of each child, $h$, is an increasing, strictly concave function of the parental time investment in the education of the child, $e$, and due to the obsolescence of human capital in a changing technological environment, a decreasing, strictly convex function of the rate of technological progress, $g$.

$$
h=h(e, g)
$$

where to assure an interior solution to the household's optimization problem, it is further assumed that $\lim _{e \rightarrow 0} h_{e}(e, g)=\infty, \lim _{e \rightarrow \infty} h_{e}(e, g)=0$, and $h(0, g)>0$ (i.e., individuals have a basic level of human capital even in the absence of parental investment in quality).

Education lessens the obsolescence of human capital in a changing technological environment. That is, the marginal productivity of parental investment in a child's human capital increases in a more rapidly changing technological environment (i.e., $h_{e g}(e, g) \equiv \partial[\partial h(e, g) / \partial e] / \partial g>$ $0)$.

The household's optimization implies, therefore, that the optimal level of children, $n$, and 
their quality, $e$, are given by

$$
\begin{aligned}
& n=\gamma /\left(\tau^{q}+\tau^{e} e\right), \\
& \tau^{e} h(e, g)=\beta h_{e}(e, g)\left(\tau^{q}+\tau^{e} e\right) .
\end{aligned}
$$

Lemma 1 Given $\left(g, \beta, \tau^{e}, \tau^{q}\right)$, there exists a unique, interior, optimal level of investment in child quality

$$
e=e\left(g, \beta, \tau^{e}, \tau^{q}\right)
$$

where $\frac{\partial e}{\partial g}>0, \frac{\partial e}{\partial \beta}>, \frac{\partial e}{\partial \tau^{q}}>, \frac{\partial e}{\partial \tau^{e}}<0$

Proof. As follows from (11), the necessary condition for the household's optimization with respect to $e$ is given by the implicit function

$$
G\left(e, g, \beta, \tau^{q}, \tau^{e}\right) \equiv \tau^{e} h(e, g)-\beta h_{e}(e, g)\left(\tau^{q}+\tau^{e} e\right)=0 .
$$

As follows from the properties of $h(e, g)$,

$$
\begin{gathered}
\lim _{e \rightarrow 0} G\left(e, g, \beta, \tau^{q}, \tau^{e}\right)<0, \\
\lim _{e \rightarrow \infty} G\left(e, g, \beta, \tau^{q}, \tau^{e}\right)>0,
\end{gathered}
$$

whereas, noting that $0<\beta<1$,

$$
\frac{\partial G\left(e, g, \tau^{q}, \tau^{e}\right)}{\partial e}=(1-\beta) \tau^{e} h_{e}(e, g)-\beta h_{e e}(e, g)\left(\tau^{q}+\tau^{e} e\right)>0 .
$$

Hence, it follows from the Intermediate Value Theorem that there exists a unique, interior, value of $e$ such that $e=e\left(g, \beta, \tau^{e}, \tau^{q}\right)$.

Furthermore, noting that the strict concavity of $h(e, g)$ in $e$ implies that $h(e, g)-h_{e}(e, g) e>$ 0 , it follows that

$$
\begin{aligned}
& \frac{\partial G\left(e, g, \tau^{q}, \tau^{e}\right)}{\partial g}=\tau^{e} h_{g}(e, g)-\beta h_{e g}(e, g)\left(\tau^{q}+\tau^{e} e\right)<0, \\
& \frac{\partial G\left(e, g, \tau^{q}, \tau^{e}\right)}{\partial \beta}=-h_{e}(e, g)\left(\tau^{q}+\tau^{e} e\right)<0, \\
& \frac{\partial G\left(e, g, \tau^{q}, \tau^{e}\right)}{\partial \tau^{q}}=-\beta h_{e}(e, g) \tau^{q}<0, \\
& \frac{\partial G\left(e, g, \tau^{q}, \tau^{e}\right)}{\partial \tau^{e}}=h(e, g)-\beta h_{e}(e, g) e>0 .
\end{aligned}
$$

Thus,

$$
\begin{aligned}
& \frac{\partial e}{\partial g}=-\frac{\partial G\left(e, g, \tau^{q}, \tau^{e}\right)}{\partial g} / \frac{\partial G\left(e, g, \tau^{q}, \tau^{e}\right)}{\partial e}>0, \\
& \frac{\partial e}{\partial \beta}=-\frac{\partial G\left(e, g, \tau^{q}, \tau^{e}\right)}{\partial \beta} / \frac{\partial G\left(e, g, \tau^{q}, \tau^{e}\right)}{\partial e}>0, \\
& \frac{\partial e}{\partial \tau^{q}}=-\frac{\partial G\left(e, g, \tau^{q}, \tau^{e}\right)}{\partial \tau^{q}} / \frac{\partial G\left(e, g, \tau^{q}, \tau^{e}\right)}{\partial e}>0, \\
& \frac{\partial e}{\partial \tau^{e}}=-\frac{\partial G\left(e, g, \tau^{q}, \tau^{e}\right)}{\partial \tau^{e}} / \frac{\partial G\left(e, g, \tau^{q}, \tau^{e}\right)}{\partial e}<0 .
\end{aligned}
$$


Lemma 2 Given $\left(g, \beta, \tau^{e}, \tau^{q}\right)$, there exists a unique, interior, optimal number of children

$$
n=\frac{\gamma}{\tau^{q}+\tau^{e} e\left(g, \beta, \tau^{e}, \tau^{q}\right)}
$$

where

- $\frac{\partial n}{\partial g}<0, \frac{\partial n}{\partial \beta}<0, \frac{\partial n}{\partial \tau^{q}}<0$,

- $\frac{\partial n}{\partial \tau^{e}}>0$ if $\left[\partial e / \partial \tau^{e}\right]\left[\tau^{e} / e\right]>-1$.

Proof. As follows from (11), noting Lemma 1, the necessary condition for the household's optimization with respect to $n$ is given by

$$
n=\frac{\gamma}{\tau^{q}+\tau^{e} e}=\frac{\gamma}{\tau^{q}+\tau^{e} e\left(g, \beta, \tau^{e}, \tau^{q}\right)}
$$

Hence,

$$
\begin{aligned}
& \frac{\partial n}{\partial g}=-\frac{\gamma \tau^{e} \frac{\partial e}{\partial g}}{\left[\tau^{q}+\tau^{e} e\left(g, \beta, \tau^{e}, \tau^{q}\right)\right]^{2}}<0 \\
& \frac{\partial n}{\partial \beta}=-\frac{\gamma \tau^{e} \frac{\partial e}{\partial \beta}}{\left[\tau^{q}+\tau^{e} e\left(g, \beta, \tau^{e}, \tau^{q}\right)\right]^{2}}<0 \\
& \frac{\partial n}{\partial \tau^{q}}=-\frac{\gamma\left[1+\tau^{e} \frac{\partial e}{\partial \tau^{q}}\right]}{\left[\tau^{q}+\tau^{e} e\left(g, \beta, \tau^{e}, \tau^{q}\right)\right]^{2}}<0
\end{aligned}
$$

whereas if $\left[\partial e / \partial \tau^{e}\right]\left[\tau^{e} / e\right]<-1$ (i.e., if the elasticity of child quality with respect to the cost of child quality is greater than one in absolute value)

$$
\frac{\partial n}{\partial \tau^{e}}=-\frac{\gamma\left[e+\tau^{e} \frac{\partial e}{\partial \tau^{e}}\right]}{\left[\tau^{q}+\tau^{e} e\left(g, \beta, \tau^{e}, \tau^{q}\right)\right]^{2}}=-\frac{\gamma e\left[1+\frac{\partial e}{\partial \tau^{e}} \frac{\tau^{e}}{e}\right]}{\left[\tau^{q}+\tau^{e} e\left(g, \beta, \tau^{e}, \tau^{q}\right)\right]^{2}}>0 .
$$

Hence, the optimal level of investment in child quality increases if:

(i) The technological environment changes more rapidly (i.e., $\left.\partial e\left(g, \beta, \tau^{e}, \tau^{q}\right) / \partial g>0\right)$;

(ii) Preferences for child quality are higher (i.e., $\left.\partial e\left(g, \beta, \tau^{e}, \tau^{q}\right) / \partial \beta>0\right)$;

(iii) The cost of raising a child (regardless of quality) increases (i.e., $\partial e\left(g, \beta, \tau^{e}, \tau^{q}\right) / \partial \tau^{q}>0$ ); or

(iv) The cost of educating a child decreases (i.e., $\left.\partial e\left(g, \beta, \tau^{e}, \tau^{q}\right) / \partial \tau^{e}<0\right)$.

Similarly, the optimal number of children declines if:

(i) The technological environment changes more rapidly (i.e., $\partial n / \partial g<0$ ); 
(ii) Preferences for child quality are higher (i.e., $\partial n / \partial \beta<0$ );

(iii) The cost of raising a child (regardless of quality) increases (i.e., $\partial n / \partial \tau^{q}<0$ ); or

(iv) The cost of educating a child increases and the elasticity of child quality with respect to the cost of child quality is smaller than one in absolute value (i.e., $\partial n / \partial \tau^{e}<0$ if $\left.\left[\partial e / \partial \tau^{e}\right]\left[\tau^{e} / e\right]>-1\right) .{ }^{16}$

Thus, the theory generates several testable implications regarding the effect of a rise in demand for education on the onset of the demographic transition: ${ }^{17}$

a. Across countries with similar sociocultural characteristics (and thus with similar non-economic factors that may affect fertility decisions):

(i) The timing of the fertility decline is inversely related to the rate of technological progress.

(ii) The level of fertility is inversely related to investment in education.

b. Within an economy:

(i) The level of fertility across households is inversely related to their level of investment in education.

(ii) An increase in the preference for educated offspring decreases fertility.

\subsection{Evidence: Education and the Demographic Transition}

Consistent with the theory, the growth rates of income per capita among Western European countries were rather similar during their demographic transition, despite large differences in their levels of income per capita. The average growth rate among northwestern European countries

\footnotetext{
${ }^{16}$ If the elasticity of child quality with respect to the cost of child quality is smaller than one (in absolute value), an increase in the cost of education increases the overall investment in child quality and thus the number of children declines. However, if the elasticity is greater than one, the number of children increases.

${ }^{17}$ In contrast to Becker and Lewis (1973), a rise in parental income (possibly due to a rise in the return to their education) does not necessarily generate a substitution from child quantity to child quality. Instead, an increase in the household's earning capacity, $y$, due to the rise in the wage per efficiency unit of labor, generates two conflicting effects. On the one hand, the rise in $y$ also generates a positive income effect that operates to increase the number of children. On the other hand, the rise in $y$ generates a negative substitution effect that reflects an increase in the opportunity cost of raising a child, $y\left[\tau^{q}+\tau^{e} e\right]$. If preferences are homothetic, the income effect and the substitution effect cancel each other. Then, the optimal number of children and their quality are independent of the parental level of income.
} 
during this period was $1.3 \%$ per year - ranging from $1.0 \%$ per year in the United Kingdom, 1.3\% in Norway, $1.4 \%$ in Finland and France, $1.5 \%$ in Sweden, to 1.6\% in Germany (Maddison, 2001). Moreover, the adverse effect of an increase in productivity in the advanced stages of development on net fertility has been established by Lehr (2009) using a pooled cross-sectional time series sample during 1960-1999, and by ? based on a sample of countries during the period 1900-1999.

Furthermore, evidence from a panel of countries during 1870-2000 demonstrates that investment in education was indeed a dominating force in the decline in fertility. In particular, educational attainment has been negatively associated with fertility, accounting for income per worker and mortality rates (Murtin, 2009). Importantly, cross-sectional evidence from France, Germany, and England supports the hypothesis that the rise in human capital formation has had an adverse effect on fertility. Becker et al. (2009) find that education stimulated a decline in fertility in Prussia during the nineteenth century. ${ }^{18}$ Similarly, Murphy (2009) finds, based on panel data from France during 1876-1896, that the level of education attainment had an adverse effect on fertility rates during France's demographic transition, accounting for income per capita, the gender literacy gap, and mortality rates.

As depicted in Figure 4.3, the decline in fertility in England was associated with a significant increase in the investment in child quality as reflected by years of schooling. In particular, Klemp and Weisdorf (2010) establish a causal effect of family sibship size on individual literacy using demographic data for 26 English parishes during 1580-1871. Exploiting exogenous variation in sibship size, stemmed from parental fecundity, they find that each additional sibling reduces literacy among all family siblings. In addition, quantitative evidence provided by Doepke (2004) suggests that educational policies aimed at promoting human capital formation played an important role in the demographic transition in England.

A direct test of the effect on fertility of the rise in the return on human capital has been conducted by Bleakley and Lange (2009) in the context of the eradication of hookworm disease in the American South (circa 1910). Noting that the eradication of this disease can be viewed as a positive shock to the return to child quality since (i) it raises the return on human capital investment, (ii) it had a very low fatality rate, and (iii) it had negligible prevalence among adults, they find that the rise in the return to child quality had a significant adverse effect on fertility

\footnotetext{
${ }^{18}$ They find that a lower cost of education, as proxied by lower land concentration, had an adverse effect on fertility and education in the middle of the nineteenth century and on the extensiveness of the fertility decline toward the end of the nineteenth century.
} 
rates. ${ }^{19}$

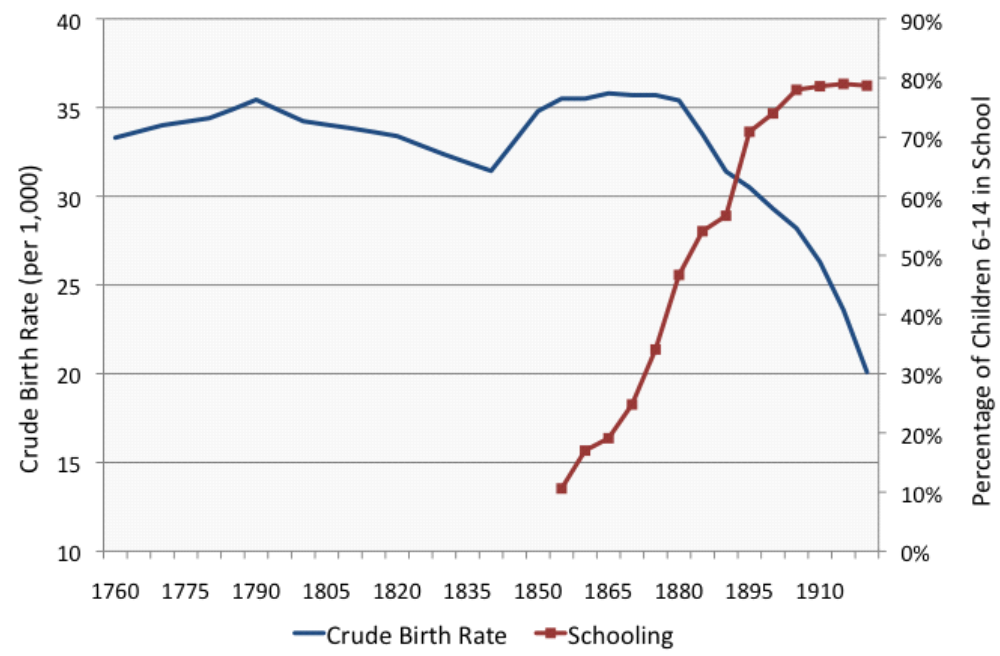

Figure 3. Investment in Human Capital and the Demographic Transition, England, 1730-1935.

Sources: Wrigley and Schofield (1981); Flora et al. (1983).

Finally, the prediction of the theory regarding the adverse effect of increased preference for educated offspring on fertility rates is also supported by the empirical evidence (Becker et al., 2009).

\subsection{Evidence: Quantity-Quality Trade-off in the Post-Demographic Transi- tion Period}

Empirical examinations of the presence of a quantity-quality trade-off in the contemporary period do not directly reflect on the importance of increased demand for education for the onset of the demographic transition. Nevertheless, they may provide an additional perspective about the mechanism as a whole.

Rosenzweig and Wolpin (1980), using the occurrence of multiple births as an exogenous source of variation in quantity, confirm the hypothesis that an exogenous increase in fertility decreases child quality. These findings were echoed by Hanushek (1992). Recently, however,

\footnotetext{
${ }^{19}$ Quantitative evidence provided by Greenwood and Seshadri (2002) is supportive of the role played by the rise in the demand for skilled labor in the demographic transition in the US. They demonstrate that the faster pace of technological progress in an industrial skilled-intensive sector as opposed to an unskilled-intensive agricultural sector generates a demographic pattern that matches the data on the US demographic transition.
} 
Black et al. (2005) and Angrist et al. (2008) have used data on twins in Norway and Israel to assess the impact of an exogenous increase in the number of children on measures of the quality of nontwins. They have found little evidence of an adverse effect on the quality of nontwins. ${ }^{20}$ In contrast, employing a similar methodology, Li et al. (2008) find a significant quantity-quality trade-off in rural China and weaker effects in urban areas. However, as asserted by Rosenzweig and Zhang (2009), since these studies ignore the impact on the quality of the twins themselves, it is essential to assess whether the closer spacing of twins and their inferior endowments affect investments in nontwins in the family and obscure the quantity-quality trade-off. Rosenzweig and Zhang (2009) find that parents do provide more human capital resources to children with higher endowments (i.e., nontwin children).

Furthermore, as elaborated in the derivation of the theory, an ideal test of the presence of a quantity-quality trade-off requires a change in the relative price of quantity or a change in the return to quality. In contrast, the effect of a change in an endogenous variable (i.e., quantity of children) requires a careful examination of the adjustment made by the household due to the exogenously imposed nonoptimal choice of quantity. The theory suggests that in sufficiently wealthy societies where intergenerational transfers take place (e.g., Israel and Norway) an unexpected birth is more likely to reduce future intergenerational transfers to the child as opposed to reducing child quality. The optimal level of investment in child quality, as other forms of investment, reflects the return on this investment. If a nonoptimal choice of quantity of children is imposed on the household (due to an unexpected birth of a child), it is not necessarily optimal for the household to reduce child quality. Instead, optimality would necessitate adjustments in other margins (intergenerational transfers or parental consumption). In particular, if parents intend to transfer income to their children in the future, the optimal investment in child quality equates the rate of return on investment in human capital to the rate of return on investment in physical capital (which is constant from the viewpoint of the individual). A shock to the quantity of children would generate an adjustment in the household's optimization. As such, a reduction in investment in child quality would be suboptimal since it would result in a higher rate of return on investment in human capital than on physical capital. ${ }^{21}$ The optimal adjustment

\footnotetext{
${ }^{20}$ Significant child allowances in these countries may mitigate the adverse effect on child quality and may therefore obscure the adverse effect of quantity on quality.

${ }^{21}$ See Galor and Moav (2004) for the optimal allocation of intergenerational transfers between investment in human capital and the transfer of physical capital.
} 
would be a reduction in intergenerational transfers, leaving investment in child quality intact. Thus, although a quantity-quality trade-off may exist (i.e., an increase in the relative price of the quantity of children or the return to quality decreases the number of children and increases investment in each child), an exogenous change in child quantity does not affect child quality. The findings of Black et al. (2005) and Angrist et al. (2008) thus have limited bearing on the presence or absence of a quantity-quality trade-off.

\section{The Rise in the Demand for Human Capital: Reinforcing Mechanisms}

The onset of the demographic transition is traced by Galor and Weil (2000) and Galor and Moav (2002) to the rise in the demand for human capital and the incentive that it provides parents to substitute quality for quantity of children. This link has been reinforced by various complementary mechanisms.

\subsection{The Decline in Child Labor}

Improvements in health infrastructure and the rise in life expectancy may have reinforced the impact of increased demand for human capital on the decline in the desired number of surviving offspring. ${ }^{22}$ Despite gradual improvements in the health environment and in life expectancy prior to the demographic transition, investment in human capital was rather insignificant as long as technological demand for human capital was limited. However, in light of the technologically based rise in demand for human capital during the second phase of the Industrial Revolution, the effect of health on the productivity of workers and pupils has increased the potential rate of return on investments in children's human capital and thus has reinforced and complemented the incentive to invest in education and its associated effect on fertility rates. ${ }^{23}$

\footnotetext{
${ }^{22}$ Hazan (2009) has argued that the lengthening of life expectancy toward the end of the nineteenth century had no effect on the length of working life and thus could not be viewed as an incentive for investment in human capital. However, as established by Sheshinski (2009), when survival probabilities rise at all ages, behavioral response depends on changes in the hazard rate. An increase in life expectancy may lead to higher investment in education. Moreover, the increase in the health of children enhanced their productivity in human capital formation and thus increased the relative return to investment in child quality (Hazan and Zoabi, 2006).

${ }^{23}$ Young (2005) argues that a widespread community infection (i.e., the AIDS epidemic in Africa) lowers fertility, both directly, through a reduction in the willingness to engage in unprotected sexual activity, and indirectly, by increasing the scarcity of labor and the value of a woman's time.
} 


\subsection{The Rise in Life Expectancy}

The improvements in health infrastructure and the rise in life expectancy may have reinforced the impact of an increase in the demand for human capital on the decline in the desired number of surviving offspring. ${ }^{24}$ Despite gradual improvements in the health environment and in life expectancy prior to the demographic transition, investment in human capital was rather insignificant as long as technological demand for human capital was limited. However, in light of the technologically-based rise in the demand for human capital during the second phase of the Industrial Revolution, the effect of health on the productivity of workers and pupils has increased the potential rate of return to investments in children's human capital and thus has reinforced and complemented the incentive to invest in education and its associated effect on fertility rates.

\subsection{Globalization}

Galor and Mountford (2006) and Galor and Mountford (2008) argue that international trade contributed to the divergence in the timing of the demographic transition and the emergence of sustained economic growth across countries. The expansion of international trade enhanced the specialization of industrial economies in the production of industrial, skill-intensive, goods. The associated rise in the demand for skilled labor has induced a gradual investment in the quality of the population, expediting a demographic transition, stimulating technological progress and further enhancing the comparative advantage of these industrial economies in the production of skill-intensive goods. In non-industrial economies, in contrast, international trade has generated an incentive to specialize in the production of unskilled-intensive, non-industrial, goods. The absence of significant demand for human capital has provided limited incentives to invest in the quality of the population and a larger share of their gains from trade has been utilized for a further increase in the size of the population, rather than in the income of the existing population. The demographic transition in these non-industrial economies has been significantly delayed, increasing further their relative abundance of unskilled labor, enhancing their comparative disadvantage in the production of skill-intensive goods, and delaying their process of development.

\footnotetext{
${ }^{24}$ Hazan (2009) has argued that the lengthening of life expectancy towards the end of the 19th century had no effect on the length of the working life and thus could not be viewed as an incentive for investment in human capital. However, the associated increase in students health enhanced their productivity in human capital formation and thus, increased the relative return to child quality (Hazan and Zoabi (2006)).
} 


\subsubsection{Anecdotal Evidence}

The contrasting process of development of the United Kingdom and India over the 19th and the 20th centuries is consistent with the proposed theory and provides an interesting case study. During the nineteenth century the United Kingdom traded manufactured goods for primary products with India. Per capita industrialization in India significantly regressed over this century whereas per capita industrialization in the UK accelerated. The process of industrialization in the United Kingdom lead to a significant increase in the demand for skilled labor in the second phase of the industrial revolution, triggering a demographic transition in the 1870s and a transition to a state of sustained economic growth. In India, in contrast, the lack of demand for skilled labor delayed the demographic transition and the transition to a sustained-growth regime to the second half of the twentieth century.

Another interesting case study providing supporting evidence for the proposed hypothesis is the economic integration of the Israeli and the West Bank economies in the aftermath of the 1967 war. Trade and factor mobility between the skilled abundant economy of Israel and the unskilled abundant economy of the West Bank shifted the West Bank economy toward further specialization in the production of primary goods, and triggered an astonishing increase in crude births rates from 22 per 1000 people in 1968 to 42 per 1000 in 1990, despite a decline in mortality rates. Thus, the gains from trade and development in the West Bank economy were partly converted into an increase in population size, nearly doubling the population in about two decades. Consistent with the proposed theory, the Palestinian uprising in the early 1990s and the gradual separation of the two economies resulted in the reduction in the crude birth rates among the Palestinian population.

\subsubsection{Empirical Examination}

Galor and Mountford (2008) use cross-country regression analysis to examine empirically the hypothesis that the effect of international trade on the demand for human capital induces a rise in fertility and a decline in human capital formation in non-industrial economies, and a decline in fertility and a rise in human capital formation in industrialized economies. The evidence suggests that indeed international trade has reinforced the initial patterns of comparative advantage and has generated a persistent effect on the distribution of population in the world economy.

The empirical analysis focuses on a recent time period in which most countries have already 
experienced their demographic transition. In particular, it examines the effect of the share of trade in GDP in 1985 on Total Fertility Rate (TFR) and on the change in the average years of schooling in industrial and non-industrial economies over the time period 1985-1990. The choice of this time period reflects the desirability of the use of the Frankel and Romer (1999) instrument for a country's intrinsic propensity to trade in 1985, so as to overcome the potential existence of omitted variables, measurement errors, and reverse causality from fertility and human capital formation to trade patterns. Furthermore, in the absence of authoritative data on the factor content of trade that would have enabled the division of the world into economies which export human capital intensive goods and those which export unskilled labor intensive goods, the hypothesis is tested on a pre-existing division of the world economy, and considers OECD economies in 1985 as those which export on average human capital intensive goods and non-OECD economies in 1985 as those which export unskilled-intensive goods.

The theory suggests that international trade, via its effect on the patterns of specialization, would increase the demand for human capital in the OECD economies and decrease the demand for human capital in non-OECD economies. This would generate a force toward a decline in fertility rates and an increase in human capital investment in OECD economies and toward a rise in fertility rates and a decline in human capital investment in non-OECD economies. In addition, however, the gains from international trade, would be expected to generate a rise in income in both OECD and non-OECD countries. In the pre-demographic transition era these gains in income would be channeled toward an increase in fertility rates. The effect of the rise in income would therefore enhance the increase in fertility rates in less developed economies and would offset some of the negative effect of the rise in the demand for human capital on fertility in developed economies.

However, in the post-demographic transition era, which is the time period that characterizes our data, the rise in income due to international trade generates, at the parental level, conflicting income and substitution effects with respect to the optimal number of children and their quality. Although, according to the theory, these effects offset one another, the rise in households' income increases the relative demand for human capital intensive goods and generates a force toward a decline in fertility and a rise in human capital investment in non-OECD economies as well as in OECD economies that have not reached their balanced growth path.

Thus, in the post-demographic transition era, the overall effect of international trade on 
fertility in OECD economies would be expected to be negative, whereas the overall effect of trade on fertility in non-OECD economies is affected by two conflicting forces. Controlling for income, however, the effect of trade on fertility is predicted to be positive in non-OECD economies and negative in OECD economies. Similarly, controlling for income, the effect of trade on human capital formation is predicted to be negative in non-OECD economies and positive in OECD economies. Furthermore, some of the variation in fertility rates across countries would reflect variation in infant mortality rates. As long as parents generate utility from the number of surviving children, the theory predicts that infant mortality rates have a positive effect on fertility rates in both OECD and non-OECD economies.

The cross-country regression analysis supports the hypothesis that international trade generates opposing effects on fertility rates and education in developed and less developed economies. As depicted in Figures 4, international trade has a positive effect on fertility in non-OECD economies and negative effect in OECD economies. Similarly, as established by Galor and Mountford (2008) international trade has a negative effect on human capital formation in non-OECD economies and a positive effect in OECD economies. 


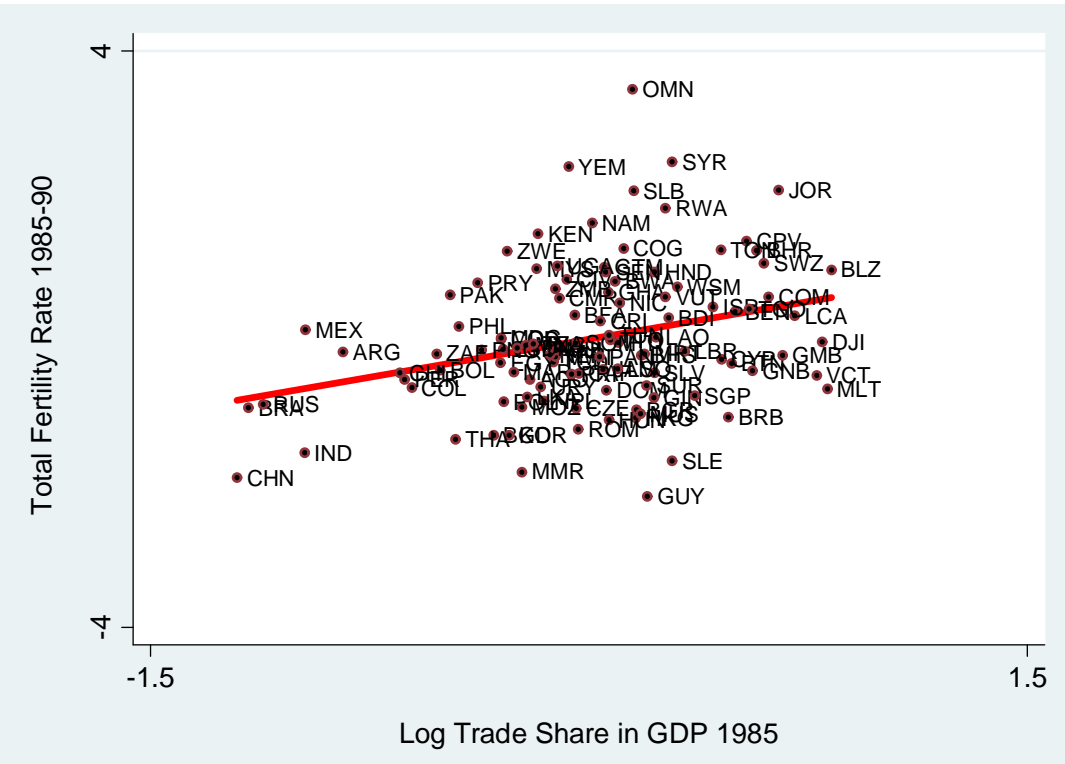

(a) Non-OECD Economies.

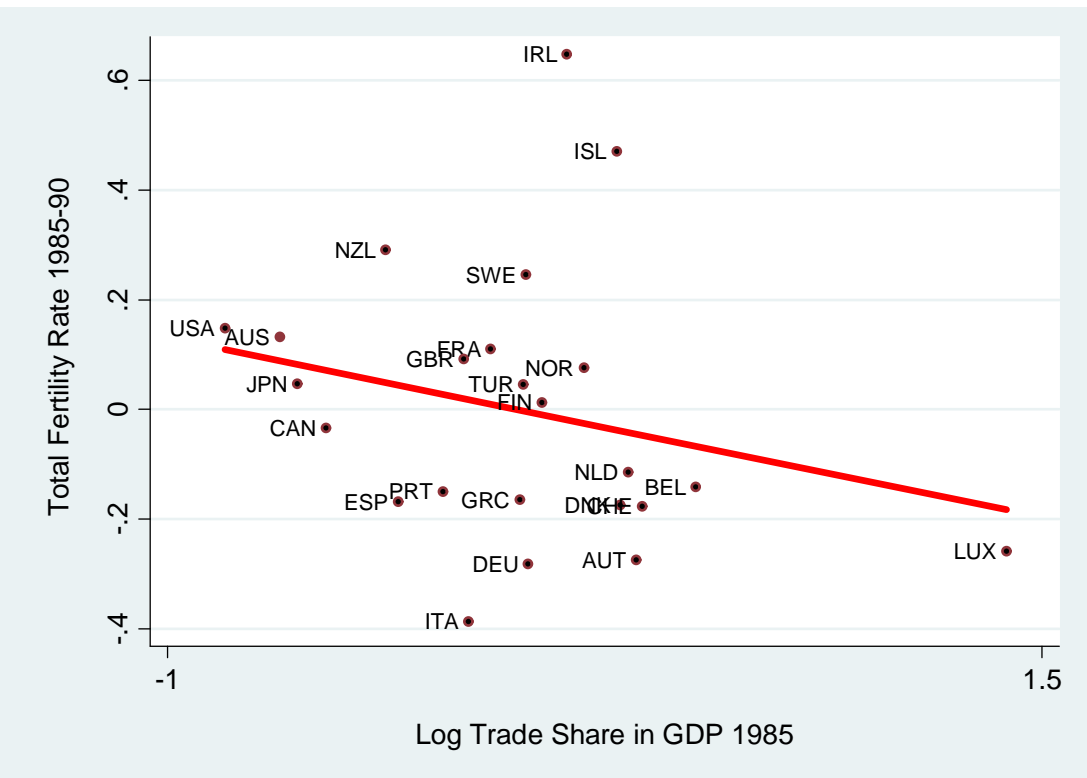

(b) OECD Economies.

Figure 4. The Effect of Trade on Fertility in OECD and non-OECD Economies.

Summary - The figure depicts the partial regression line for the effect of trade share in GDP in 1985 on Total Fertility Rate in the period 1985-1990 in Non-OECD (top panel) and OECD economies (bottom panel) while controlling for log GDP per capita and infant mortality rate in 1985. 


\subsection{Evolution of Preferences for Offspring's Quality}

The impact of the increased demand for human capital on the decline in the desired number of surviving offspring may have been magnified by the evolution of preferences toward child quality. These evolutionary processes conceivably have been driven by cultural and religious movements as well as by the forces of natural selection.

Galor and Moav (2002) propose that during the Malthusian Epoch individuals with a higher valuation of offspring quality gained an evolutionary advantage and their representation in the population gradually increased. They argue that the agricultural revolution facilitated division of labor, which fostered trade relationships among individuals and communities. It enhanced the complexity of human interaction and raised the return on human capital. The prevalence of preferences for child quality in the population lagged behind the evolutionarily optimal level, and individuals with traits of higher valuation of offspring quality generated higher income and, in the Malthusian Epoch (when income had a positive effect on fertility), a larger number of offspring. ${ }^{25}$ Thus, the Malthusian pressure gradually increased the proportion of individuals whose preferences were biased toward child quality. This evolutionary process was reinforced by its interaction with economic forces. As the fraction of individuals with high valuation of quality increased, technological progress intensified, raising further the demand for human capital. The increase in the rate of return on human capital along with the increase in the bias toward quality in the population reinforced the substitution toward child quality, setting the stage for a more rapid decline in fertility and a significant increase in the investment in human capital.

Religious movements (e.g., Judaism [(Botticini and Eckstein, 2005)] and Protestantism [(Becker and Woessmann, 2009)]) and the Age of Enlightenment have also contributed to the demographic transition through their effects on preferences for education. In particular, as established empirically by Becker et al. (2009), a rise in preferences for education (proxied by concentric diffusion of Protestantism in Prussia around Luther's city of Wittenberg) had an adverse effect on fertility rates during the middle of the nineteenth century in Prussia.

\footnotetext{
${ }^{25}$ As long as the bias toward child quality is moderate, the additional income generated dominates that bias toward quality and allows for a higher reproduction success rate.
} 


\section{The Decline in the Gender Gap}

The rise in demand for human capital and its impact on the decline in the gender wage gap during the nineteenth and the twentieth centuries have contributed to the onset of the demographic transition. In particular, the rise in women's relative wages during the process of development, its positive impact on female labor force participation, and its adverse effect on fertility rates have been at the center of a complementary theory of the demographic transition that generates the observed hump-shaped relationship between income per capita and population growth.

A pattern of rising relative wages for women and declining fertility rates has been observed in a large number of developed and less developed economies. In particular, as depicted in Figure 4.4, this pattern was observed in the United States during $1800-1940 .^{26}$

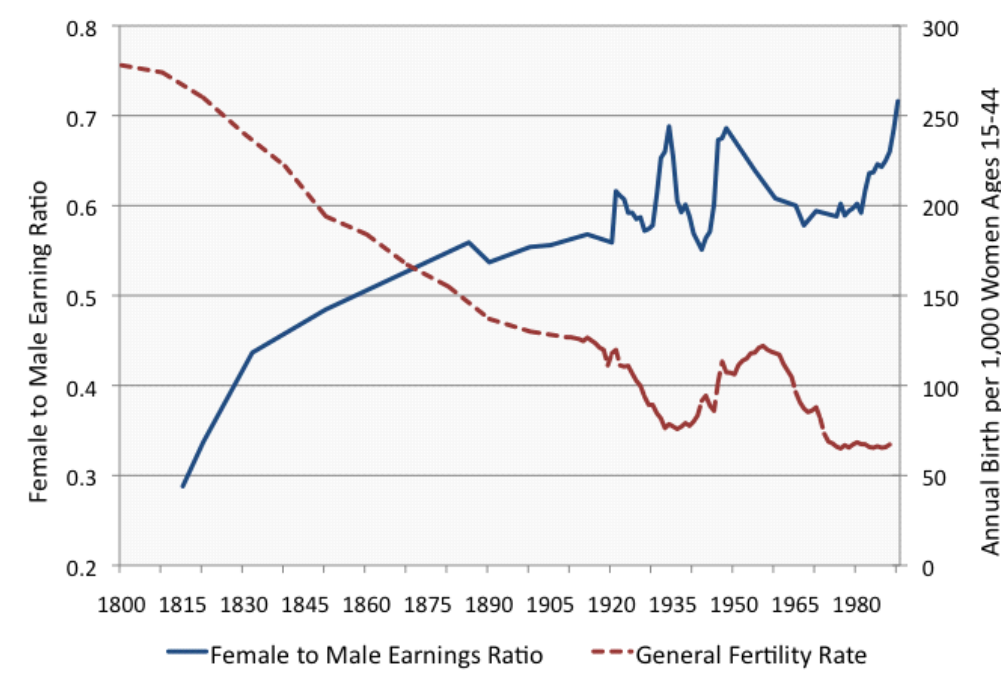

Figure 5. Female Relative Wages and Fertility Rates: United States 1800-1990.

Source: U.S. Bureau of the Census (1975) and Hernandez (2000).

In addition, the process of development has been associated with a gradual decline in the gender gap in human capital formation. As depicted in Figure 4.5, the literacy rate among women in England, which was only $76 \%$ of that of men in 1840, grew rapidly during the nineteenth century and reached the male level in 1900.

\footnotetext{
${ }^{26}$ For an extensive analysis of the pattern of fertility in the United States during 1826-1960, see Greenwood et al. (2005) and Jones and Tertilt (2006).
} 


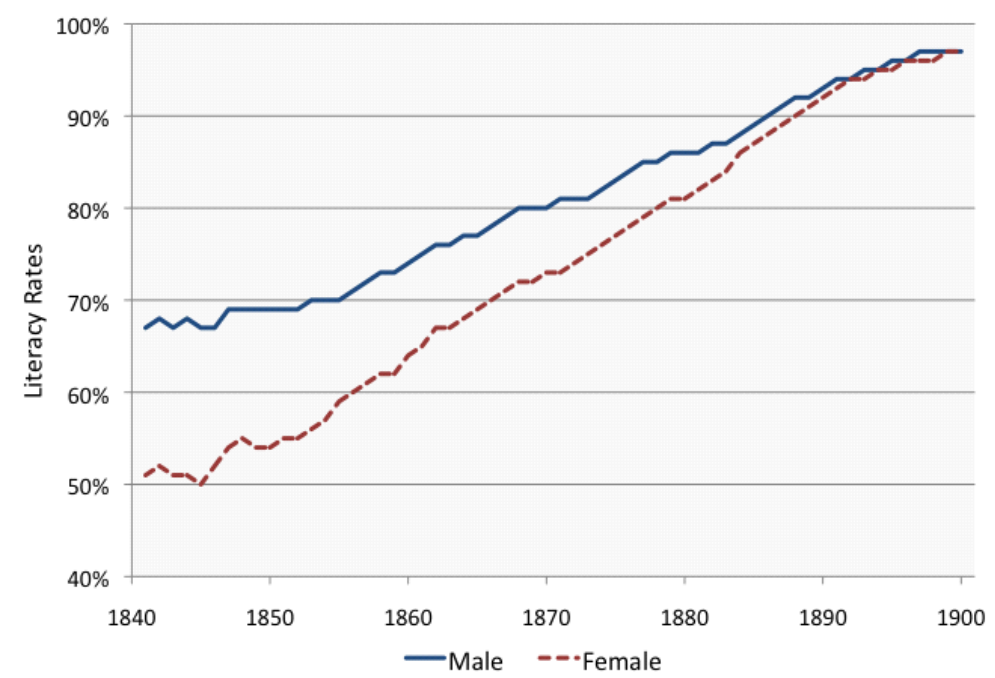

Figure 6. The Decline in the Human Capital Gap between Male and Female: England 1840-1900.

Source: Cipolla (1969).

\subsection{The Theory and its Testable Predictions}

The role that the decline in the gender wage gap played in the onset of the demographic transition has been examined by Galor and Weil (1996). They argue that technological progress and capital accumulation in the process of industrialization increased the relative wages of women and triggered the onset of the demographic transition. They maintain that technological progress, along with physical capital accumulation, complemented mentally-intensive tasks more than physicallyintensive tasks in the production process, raising the return to brain relative to brawn. Thus, in light of the comparative physiological advantage of men in physically intensive tasks and of women in mentally intensive tasks, the demand for women's labor gradually increased in the industrial sector, decreasing the gender wage gap.

In the early stages of industrialization, as long as the rise in women's wages was insufficient to induce a significant increase in women's labor force participation, fertility increased due to the income effect generated by the rise in men's wages in the increasingly more productive industrial sector. Ultimately, however, the rise in women's relative wages was sufficient to induce a significant increase in their labor force participation. This process increased the cost of 
child rearing proportionately more than the increase in household's income, triggering a fertility decline. Moreover, the rise in demand for human capital in the process of development induced a gradual improvement in women's education. It raised the opportunity cost of raising children more than the increase in household income, and reinforced the fertility decline and the rise in female labor force participation. ${ }^{27}$.

Consider households that generate utility from consumption, $c$, and the number of (surviving) children, $n$. Each household consists of a man and a woman. The man's wage is $w^{M}$ and the woman's wage is $w^{F}$ (if they devote their entire time for labor force participation). Suppose that only women raise children and the cost associated with raising each child is a fraction $\tau$ of a woman's time endowment. Hence, the household's budget constraint is

$$
\tau w^{F} n+c \leq w^{F}+w^{M}
$$

where the price of a child is the opportunity cost associated with raising a child, $\tau w^{F}$.

Hence, a rise in the wages of women, $w^{F}$, generates two conflicting effects. On the one hand, the rise in $w^{F}$ generates a positive income effect that operates to increase the number of children (as long as children are viewed as a normal good). On the other hand, the rise in $w^{F}$ generates a negative substitution effect that reflects the increase in the opportunity cost of raising children, $\tau w^{F}$. If preferences are homothetic, then the substitution effect necessarily dominates, since an increase in $w^{F}$ increases the opportunity cost of raising children proportionately more than the household's income. Fertility therefore declines and women's labor force participation increases.

Thus, unlike the single-parent model in which an increase in income generates conflicting income and substitution effects that cancel one another if preferences are homothetic, in the two-parent household model, if most of the burden of child rearing is placed on women, a rise in women's relative wages increases the opportunity cost of raising children more than household income, generating a pressure to reduce fertility.

\subsection{The Evidence}

The role of the decline in the gender wage gap in the demographic transition is supported empirically. Schultz (1985) finds that an increase in the relative wages of women played an important role in Sweden's fertility transition, and Murphy (2009) suggests, based on panel data from

\footnotetext{
${ }^{27}$ See also Goldin (1990) and Lagerlöf (2003).
} 
France during 1876-1896, that a reduction in the gender literacy gap had an adverse effect on fertility during France's demographic transition, accounting for income per capita, educational attainment, and mortality rates. ${ }^{28}$

\section{The Old-Age Security Hypothesis}

The old-age security hypothesis has been proposed as an additional mechanism for the onset of the demographic transition. It suggests that in the absence of capital markets which permit intertemporal lending and borrowing, children serve as an asset that permit parents to transfer income to old age. ${ }^{29}$ Hence, the establishment of capital markets in the process of development reduced this motivation for rearing children, contributing to the demographic transition.

Although old-age support is a plausible element that may affect the level of fertility, it appears as a minor force in the context of the demographic transition. First, since there are only rare examples in nature of offspring that support their parents in old age, it appears that old-age support cannot be the prime motivation for child rearing. Second, institutions supporting individuals in their old age were formed well before the demographic transition. For instance, evidence suggests that, as early as the sixteenth century, parents in England did not rely on support from children in their old age (Pelling and Smith, 1991; Hindle, 2004). In particular, the Poor Law Act of 1601 was interpreted by the English courts as giving the impoverished parent no claims for assistance from a child, but instead a claim for assistance from the community (Pelling and Smith, 1991).

The rise in fertility rates prior to the demographic transition, in a period of improvements in credit markets, raises further doubts about the significance of this mechanism. Moreover, cross-sectional evidence shows that in the pre-demographic transition era wealthier individuals, who presumably had better access to credit markets, had a larger number of surviving offspring, increasing the skepticism about the importance of this hypothesis. ${ }^{30}$ Thus the decline in the importance of old-age support is unlikely to be a major force behind the significant reduction in fertility - at a rate of 30-50\% - that occurred during the demographic transition.

\footnotetext{
${ }^{28}$ In the contemporary era, Heckman and Walker (1990) find a negative effect of women's wages and a positive effect of men's income on birth rates.

${ }^{29}$ See Neher (1971) and Caldwell (1976) for earlier studies and Boldrin and Jones (2002) for a recent quantitative analysis.

${ }^{30}$ It should be noted, however, that if the wealth of the rich is based on nonwage income, it would be associated with a pure income effect, which could result in higher fertility rates, despite a reduced need for old-age support.
} 


\section{The Demographic Transition and the Origins of Modern Growth}

Unified Growth Theory (Galor and Weil, 1999, 2000; Galor and Moav, 2002; Galor and Mountford, 2008; Galor, 2005, 2010) suggests that the transition from stagnation to growth is an inevitable by-product of the process of development. It argues that the inherent Malthusian interaction between the rate of technological progress and the size and the composition of the population accelerated the pace of technological progress and ultimately raised the importance of human capital in the rapidly changing technological environment. The rise in the demand for human capital and its impact on human capital formation triggered a reduction in fertility rates and population growth and further technological advances. ${ }^{31}$ The demographic transition has enabled economies to divert a larger share of the fruits of factor accumulation and technological progress from fueling population growth toward the enhancement of human capital formation and income per capita, thus paving the way for the emergence of sustained economic growth.

Thus, Unified Growth Theory suggests that the demographic transition played an important role in the emergence of modern growth. Indeed, cross-country evidence, depicted in Figure 7, shows that contemporary income per capita and education are significantly and positively associated with the time elapsed since the demographic transition.

\footnotetext{
${ }^{31}$ Clearly, the increased demand for human capital has not necessarily resulted in an increase in the rate of return to human capital due to institutional changes (e.g., the provision of public education) that lowered the cost of investment in human capital and facilitated a massive increase in the supply of education (Galor, 2005, Section 2.3.3.).
} 

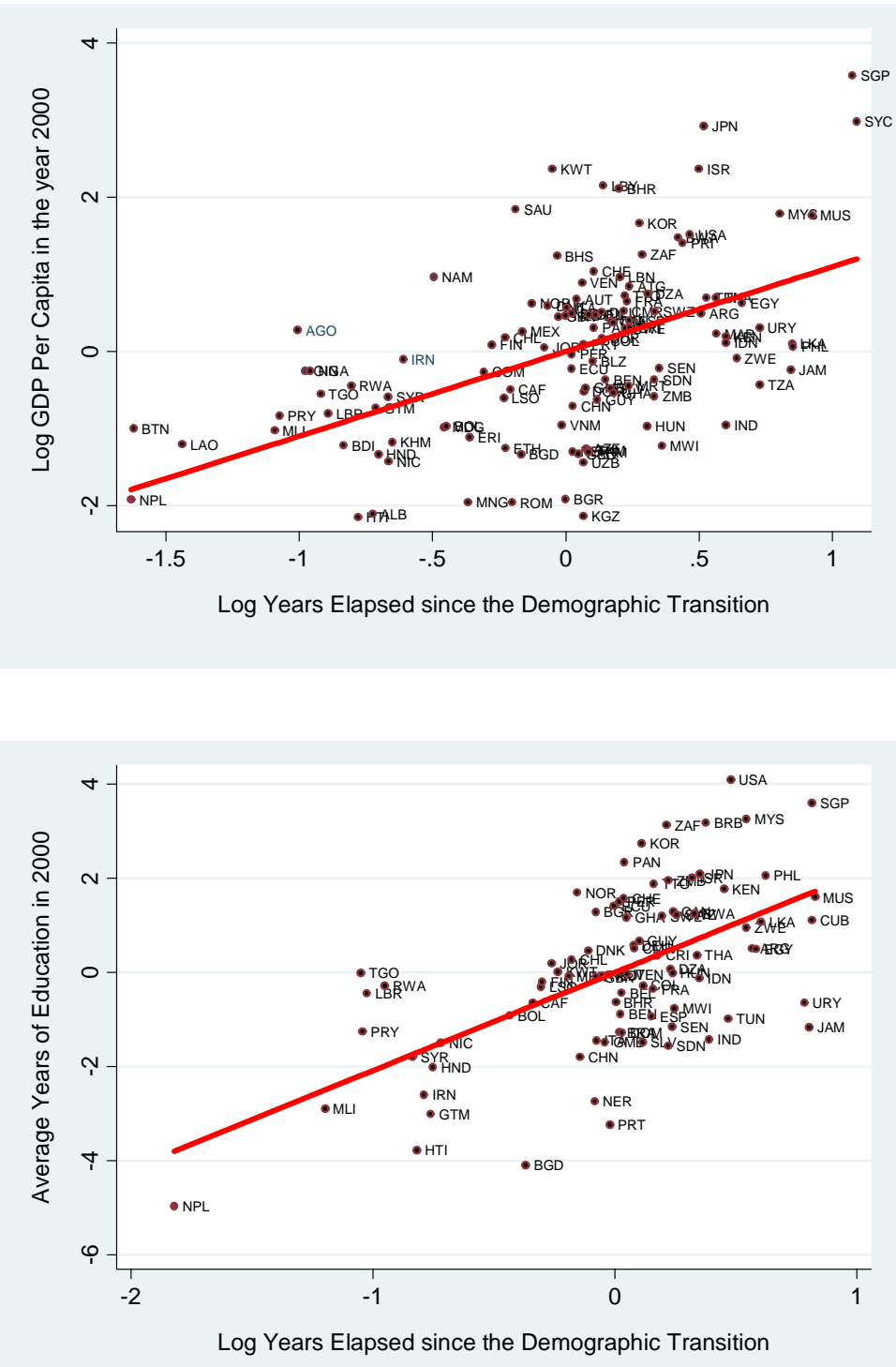

Figure 7. Education and Income Per Capita in 2000 and its association with Time Elapsed since the Demographic Transition. ${ }^{32}$

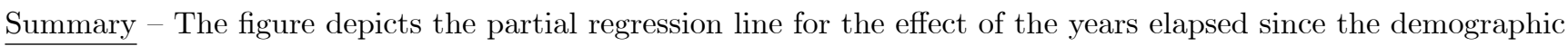
transition on income per capita in the year 2000 (top panel), and average years of education in the year 2000 (bottom panel) while controlling for the absolute latitude, and continental fixed effects.

\footnotetext{
${ }^{32}$ The data on the time elapsed since the demographic transition is derived from Reher (2004).
} 


\section{Concluding Remarks}

The old-age security hypothesis has been proposed as an additional mechanism for the onset of the demographic transition. It suggests that in the absence of capital markets which permit intertemporal lending and borrowing, children serve as an asset that permit parents to transfer income to old age. ${ }^{33}$ Hence, the establishment of capital markets in the process of development reduced this motivation for rearing children, contributing to the demographic transition.

Although old-age support is a plausible element that may affect the level of fertility, it appears as a minor force in the context of the demographic transition. First, since there are only rare examples in nature of offspring that support their parents in old age, it appears that old-age support cannot be the prime motivation for child rearing. Second, institutions supporting individuals in their old age were formed well before the demographic transition. For instance, evidence suggests that, as early as the sixteenth century, parents in England did not rely on support from children in their old age (Pelling and Smith, 1991; Hindle, 2004). In particular, the Poor Law Act of 1601 was interpreted by the English courts as giving the impoverished parent no claims for assistance from a child, but instead a claim for assistance from the community (Pelling and Smith, 1991).

The rise in fertility rates prior to the demographic transition, in a period of improvements in credit markets, raises further doubts about the significance of this mechanism. Moreover, cross-sectional evidence shows that in the pre-demographic transition era wealthier individuals, who presumably had better access to credit markets, had a larger number of surviving offspring, increasing the skepticism about the importance of this hypothesis. ${ }^{34}$ Thus the decline in the importance of old-age support is unlikely to be a major force behind the significant reduction in fertility - at a rate of 30-50\% - that occurred during the demographic transition.

\footnotetext{
${ }^{33}$ See Neher (1971) and Caldwell (1976) for earlier studies and Boldrin and Jones (2002) for a recent quantitative analysis.

${ }^{34}$ It should be noted, however, that if the wealth of the rich is based on nonwage income, it would be associated with a pure income effect, which could result in higher fertility rates, despite a reduced need for old-age support.
} 


\section{References}

Angrist, J. D., Lavy, V. and Schlosser, A. (2008). New evidence on the Causal Link Between the Quantity and Quality of Children.

Becker, G. S. (1960). An economic analysis of fertility, in G. S. Becker (ed.), Demographic and Economic Change in Developed Countries, Princeton University Press, pp. 209-231.

Becker, G. S. (1981). A Treatise on the Family, Harvard University Press, Cambridge MA.

Becker, G. S. and Lewis, H. G. (1973). On the interaction between the quantity and quality of children, Journal of Political Economy 81(2, Part II): S279-S288.

Becker, G. S., Murphy, K. M. and Tamura, R. (1990). Human capital, fertility, and economic growth, Journal of Political Economy 98(5): S12-S37.

Becker, S. O., Cinnirella, F. and Woessmann, L. (2009). The trade-off between fertility and education: Evidence from before the demographic transition. CESifo Working Paper No. 2775 .

Becker, S. O. and Woessmann, L. (2009). Was Weber Wrong? A Human Capital Theory of Protestant Economic History, Quarterly Journal of Economics 124(2): 531-596.

Black, S. E., Devereux, P. J. and Salvanes, K. G. (2005). The more the merrier? the effect of family size and birth order on children's education, Quarterly Journal of Economics 120(2): 669-700.

Bleakley, H. and Lange, F. (2009). Chronic Disease Burden and the Interaction of Education, Fertility, and Growth, Review of Economics and Statistics 91(1): 52-65.

Boldrin, M. and Jones, L. E. (2002). Mortality, Fertility, and Saving in a Malthusian Economy, Review of Economic Dynamics 5(4): 775-814.

Botticini, M. and Eckstein, Z. (2005). Jewish occupational selection: education, restrictions, or minorities?, Journal of Economic History 65(4): 922-948.

Brown, J. C. and Guinnane, T. W. (2007). Regions and Time in the European Fertility Transition: Problems in the Princeton Project's Statistical Methodology, Economic History Review 60(3): 574-595. 
Caldwell, J. C. (1976). Toward a Restatement of Demographic Transition Theory, Population and Development Review 2(3-4): 321-366.

Chesnais, J. (1992). The Demographic Transition: Stages, Patterns, and Economic Implications, Clarendon Press.

Cipolla, C. M. (1969). Literacy and Development in the West, Penguin Books, Harmondsworth, Middlesex.

Doepke, M. (2004). Accounting for Fertility Decline During the Transition to Growth, Journal of Economic Growth 9(3): 347-383.

Doepke, M. (2005). Child Mortality and Fertility Decline: Does the Barro-Becker Model Fit the Facts?, Journal of Population Economics 18(2): 337-366.

Eckstein, Z., Mira, P. and Wolpin, K. (1999). A Quantitative Analysis of Swedish Fertility Dynamics: 1751-1990, Review of Economic Dynamics 2(1): 137-165.

Fernández-Villaverde, J. (2001). Was Malthus Right? Economic Growth and Population Dynamics. Working Paper, Department of Economics, University of Pennsylvania.

Flora, P., Kraus, F. and Pfenning, W. (1983). State Economy and Society in Western Europe 1815-1975, Volume 1.

Frankel, J. A. and Romer, D. (1999). Does Trade Cause Growth?, American Economic Review 89(3): 379-399.

Galor, O. (2005). From Stagnation to Growth: Unified Growth Theory, Handbook of Economic Growth, Vol. IA, Elsevier North-Holland, Amsterdam, The Netherlands.

Galor, O. (2010). The 2008 Lawrence R. Klein Lecture - Comparative Economic Development: Insights from Unified Growth Theory, International Economic Review 51(1): 1-44.

Galor, O. and Michalopoulos, S. (2006). The Evolution of Entrepreneurial Spirit and the Process of Development. Working Paper, Department of Economics, Brown University.

Galor, O. and Moav, O. (2002). Natural Selection and the Origin of Economic growth, Quarterly Journal of Economics 117(4): 1133-1191. 
Galor, O. and Moav, O. (2004). From Physical to Human Capital Accumulation: Inequality and the Process of Development, Review of Economic Studies 71(4): 1001-1026.

Galor, O. and Mountford, A. (2006). Trade and the Great Divergence: The Family Connection, American Economic Review 96(2): 299-303.

Galor, O. and Mountford, A. (2008). Trading Population for Productivity: Theory and Evidence, Review of Economic Studies 75(4): 1143-1179.

Galor, O. and Weil, D. N. (1996). The Gender Gap, Fertility, and Growth, American Economic Review 86(3): 374-387.

Galor, O. and Weil, D. N. (1999). From Malthusian Stagnation to Modern Growth, American Economic Review 89(2): 150-154.

Galor, O. and Weil, D. N. (2000). Population, Technology, and Growth: From Malthusian Stagnation to the Demographic Transition and Beyond, American Economic Review 90(4): 806828.

Goldin, C. (1990). Understanding the Gender Gap: An Economic History of American Women, Oxford University Press, New York.

Greenwood, J. and Seshadri, A. (2002). The US Demographic Transition, American Economic Review 92(2): 153-159.

Greenwood, J., Seshadri, A. and Vandenbroucke, G. (2005). The Baby Boom and Baby Bust, American Economic Review 95(1): 183-207.

Guinnane, T. W., Okun, B. S. and Trussell, J. (1994). What Do We Know About the Timing of Fertility Transitions in Europe?, Demography 31(1): 1-20.

Hanushek, E. A. (1992). The Trade-Off between Child Quantity and Quality, Journal of Political Economy 100(1): 84-117.

Hazan, M. (2009). Longevity and Lifetime Labor Supply: Evidence and Implications, Econometrica $\mathbf{7 7}(6)$ : 1829-1863.

Hazan, M. and Zoabi, H. (2006). Does Longevity Cause Growth? A Theoretical Critique, Journal of Economic Growth 11(4): 363-376. 
Heckman, J. J. and Walker, J. R. (1990). The Relationship between Wages and Income and the Timing and Spacing of Births: Evidence from Swedish Longitudinal Data, Econometrica 58(6): 1411-1441.

Hernandez, D. J. (2000). Trends in the well being of America's children and youth.

Hindle, S. (2004). On the Parish: The Micro-Politics of Poor Relief in Rural England c. 15501750, Clarendon Press, Oxford.

Jones, L. E. and Tertilt, M. (2006). An Economic History of Fertility in the US: 1826-1960. NBER Working Paper No. 12796.

Kalemli-Ozcan, S. (2002). Does the Mortality Decline Promote Economic Growth?, Journal of Economic Growth 7(4): 411-439.

Klemp, M. P. B. and Weisdorf, J. L. (2010). The Child Quantity-Quality Trade-off: Evidence from the Population History of England. Mimeo, Department of Economics, University of Copenhagen.

Lagerlöf, N.-P. (2003). Gender equality and long-run growth, Journal of Economic Growth 8(4): $403-426$.

Lehr, C. S. (2009). Evidence on the Demographic Transition, Review of Economics and Statistics 91(4): $871-887$.

Li, H., Zhang, J. and Zhu, Y. (2008). The Quantity-Quality Trade-off of Children in a Developing Country: Identification Using Chinese Twins, Demography 45(1): 223-243.

Maddison, A. (2001). The World Economy: A Millennial Perspective, OECD, Paris.

Maddison, A. (2008). The West and the Rest in the World Economy: 1000-2030, World Economics 9(4): 75-99.

Murphy, T. E. (2009). Old Habits Die Hard (Sometimes): What Can Département Heterogeneity Tell Us About the French Fertility Decline?, Technical report, MIMEO.

Murtin, F. (2009). On the demographic transition. OECD. 
Neher, P. A. (1971). Peasants, Procreation, and Pensions, American Economic Review 61(3): 380389.

Pelling, M. and Smith, R. M. (1991). Life, death and the elderly: historical perspectives, Routledge, London.

Reher, D. S. (2004). The Demographic Transition Revisited as a Global Process, Population Space and Place 10: 19-42.

Rosenzweig, M. R. and Wolpin, K. I. (1980). Testing the Quantity-Quality Fertility Model: The Use of Twins as a Natural Experiment, Econometrica 48(1): 227-240.

Rosenzweig, M. R. and Zhang, J. (2009). Do population control policies induce more human capital investment? twins, birth weight and china's "one-child" policy, Review of Economic Studies 76(3): 1149-1174.

Schultz, T. P. (1985). Changing World Prices, Women's Wages, and the Fertility Transition: Sweden, 1860-1910, Journal of Political Economy 93(6): 1126-1154.

Schultz, T. P. (1997). Demand for Children in Low Income Countries, Handbook of Population and Family Economics 1: 349-430.

Sheshinski, E. (2009). Uncertain Longevity and Investment in Education.

U.S. Bureau of the Census (1975). Historical Statistics of the United States: Colonial Times to 1970, part 1, Series D 830-844, p.172.

Wrigley, E. A. and Schofield, R. (1981). The Population History of England, 1541-1871: A Reconstruction, Cambridge University Press.

Young, A. (2005). The Gift of the Dying: The Tragedy of AIDS and the Welfare of Future African Generations*, Quarterly Journal of Economics 120(2): 423-466. 